\title{
On the Electrical Properties of $\mathrm{AgNO}_{3}, \mathrm{TINO}_{3}$, and $\mathrm{NH}_{4} \mathrm{NO}_{3}$
}

\author{
J H. FERMOR and A. K J EKSH US
}

Kjemisk Institutt, Universitetet i Oslo, Blindern, Oslo 3, Norway

\begin{abstract}
Values of the dielectric constant and resistivity measured at $1 \mathrm{kHz}$ are presented for polycrystalline $\mathrm{AgNO}_{3}, \mathrm{TINO}_{3}$, and $\mathrm{NH}_{4} \mathrm{NO}_{3}$ below room temperature. Results are also given for $\mathrm{AgNO}_{3}$ and $\mathrm{TlNO}_{3}$ in hitherto unexplored regions above room temperature. The data show dielectric transitions in $\mathrm{AgNO}_{3}, \mathrm{TINO}_{3}$, and $\mathrm{NH}_{4} \mathrm{NO}_{3}$, with the critical temperatures $-35,-35$, and $-32^{\circ} \mathrm{C}$, respectively. Previously published values of the heat capacity of $\mathrm{TINO}_{3}$ are examined, and shown to contain an anomaly at $\sim-35^{\circ} \mathrm{C}$ which appears to be associated with the dielectric transition there. Consideration of the present and other results for $\mathrm{NH}_{4} \mathrm{NO}_{3}$ leads to the conclusion that a previously detected transition in the dielectric constant at $-32^{\circ} \mathrm{C}$ on cooling is of the same character as those found at comparable temperatures in other univalent nitrates, rather than a consequence of the IV $\rightarrow \mathrm{V}$ structural transition. A maximum in the dielectric constant of $\mathrm{AgNO}_{3}$ is found at $110^{\circ} \mathrm{C}$.
\end{abstract}

Two structural phases have been identified hitherto in solid $\mathrm{AgNO}_{3}$ at atmospheric pressure. On heating samples from room temperature, the calorimetrically determined phase II $\rightarrow I$ transition temperature is reported as 158.9 to $160.6^{\circ} \mathrm{C},{ }^{1}$ in good agreement with that given by Bridgman, ${ }^{2,3}$ who identified four structural modifications at pressures of up to $50 \mathrm{kbar}$. The phase diagram for $\mathrm{AgNO}_{3}$ is of quite a different form from that for $\mathrm{TINO}_{3}$, whose properties closely resemble those of $\mathrm{RbNO}_{3}$ and $\mathrm{CsNO}_{3}$, however. Measurements of specific heat from 15 to $300 \mathrm{~K}^{4}$ do not show any anomalies which could indicate additional phase transformations at atmospheric pressure.

The melting point of carefully dried $\mathrm{AgNO}_{3}$ is reported to be $209.6^{\circ} \mathrm{C} .{ }^{5}$ Appreciable decomposition of the melt has been reported for temperatures in the range 305 to $450^{\circ} \mathrm{C}, 6$, ? although the density and electrical conductivity were found to be reversible for temperature cycles with a maximum temperature of $320^{\circ} \mathrm{C} .{ }^{8} \mathrm{X}$-Ray measurements on the solid were, however, affected by decomposition of phase I crystals. ${ }^{\circ}$

Phase I $\mathrm{AgNO}_{3}$ has trigonal symmetry, ${ }^{9}$ whereas phase II is orthorhombic. ${ }^{10,11}$ This phase is weakly birefringent, and has rather high values of refractive indices ${ }^{12}$ compared, for example, with those for $\mathrm{KNO}_{3}$ in the orthorhombic phase II. ${ }^{13}$

The large refractive indices of $\mathrm{AgNO}_{3}$ are mainly due to the large electronic polarizability of $\mathrm{Ag}^{+}$compared with that for $\mathrm{K}^{+}$, the values of this parameter having been given as 2.4 and $1.33 \AA^{3}$, respectively. ${ }^{14}$ This, together with the 
distinctive phase diagram, suggests that the lattice bonding and hence also the electrical properties of $\mathrm{AgNO}_{3}$ might differ considerably from those of the alkali metal nitrates. In order to test this point, it is of interest to compare the frequencies of a lattice mode of vibration for the various compounds. The frequencies of strong absorption peaks of this part of the IR spectrum are shown as a function of the cation radius for $\mathrm{LiNO}_{3}, \mathrm{NaNO}_{3}, \mathrm{AgNO}_{3}, \mathrm{KNO}_{3}$, TiNO ${ }_{3}$, and $\mathrm{NH}_{4} \mathrm{NO}_{3}$ in Fig. 1. It is seen that the frequency varies regularly

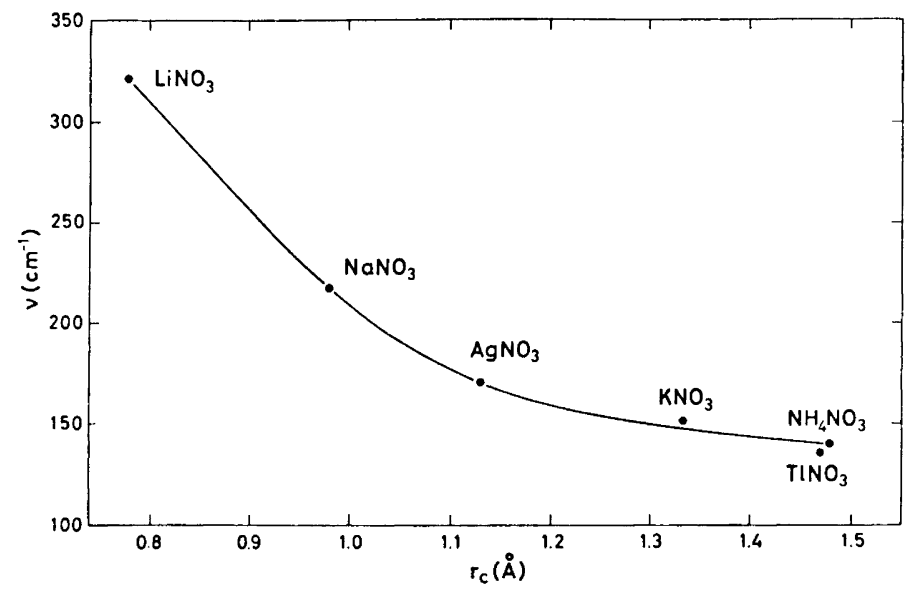

Fig. 1. A lattice mode frequency $v$ for univalent nitrates at room temperature versus cation radius $r_{c}$. The value of $v$ for $\mathrm{NH}_{4} \mathrm{NO}_{3}$ is from Landolt-Börnstein ${ }^{15}$ and Newman and Halford; ${ }^{16}$ for $\mathrm{TlNO}_{3}$, Newman and Halford; ${ }^{16}$ the remaining data are taken from Ferraro and Walker. ${ }^{17}$

with cation radius, and therefore with the anion-cation separation. Thus it seems from this dynamic property of the lattice that the interionic bonding is of a uniform nature in the compounds, and it is to be expected that the electrical among other ionic properties of $\mathrm{AgNO}_{3}$ will conform with those of the alkali metal nitrates.

According to dilatometric measurements, the volume expansion coefficient of $\mathrm{AgNO}_{3}$ drops sharply at the II $\rightarrow$ I transition or a few degrees above. ${ }^{18}$ Sparse d.c. two-terminal resistivity data for $t>140^{\circ} \mathrm{C}$ indicate a sharp minimum at the I $\rightarrow$ II transition..$^{18}$ Measurements of a.c. conductivity have been obtained in the vicinity of the melting point. ${ }^{19}$ The dielectric constant $\epsilon$ has been given as 9.0 at $20^{\circ} \mathrm{C}$ for a measuring frequency of $3 \mathrm{MHz} .^{20}$

By means of optical microscopy, it was shown that $\mathrm{TlNO}_{3}$ adopts three modifications between room temperature and the melting point, the structural symmetries in order of increasing temperature being orthorhombic, rhombohedral, and cubic.21 The cubic phase I was confirmed to be optically isotropic, the melting point being $210.4^{\circ} \mathrm{C} . .^{22-24}$ 
Differential thermal analysis has showed the III $\rightarrow$ II transition temperature to be $79^{\circ} \mathrm{C}$, and II $\rightarrow$ I at $144^{\circ} \mathrm{C}$, the II $\rightarrow$ III transition being diffuse..$^{22} \mathrm{~A}$ calorimetric investigation gave the $\mathrm{I} \rightarrow \mathrm{II}$ transition temperature range as 142.5 to $143.8^{\circ} \mathrm{C}$, compared with the value $144.6^{\circ} \mathrm{C}$ given by Bridgman. ${ }^{2}$ The latter author found the II $\rightarrow$ III transition to occur at $75^{\circ} \mathrm{C}$ and recorded no additional phases at pressures of up to $12 \mathrm{kbar}$.

The orthorhombic, room temperature phase III has been studied by several authors using X-ray diffraction. ${ }^{22,25-27}$ From measurements of the anisotropic IR absorption spectra for this phase, the directions of the two-fold axes of the nitrate groups, which lie in planes equidistant from those through the metal atoms, were deduced to bisect the angle between the $a$ and $b$ axes; the molecular planes being tilted about these directions. ${ }^{16}$

A large polarizability of $\mathrm{Tl}^{+28}$ is reflected in both the refractive index ${ }^{29}$ and the dielectric constant at room temperature (16.5), ${ }^{20}$ but as in the case of $\mathrm{AgNO}_{3}$, this does not appear to influence the IR response, as may be seen in Fig. 1 .

A determination of the electrical conductivity at $900 \mathrm{~Hz}$ and $30 \mathrm{kHz}$ did not show the III $\rightarrow$ II transition, but the II $\rightarrow$ I transition produced an overall increase of $\sim 1.5$ orders of magnitude in $\sigma .^{30}$ Later measurements showed a decrease in $\sigma$ by a factor of 200 at III $\rightarrow$ II, ${ }^{22}$ probably due to a partial disintegration of the sample, which may have included water. An increase in $\sigma$ of two orders of magnitude was noted at II $\rightarrow \mathrm{I}$.

The values of the specific heat $C_{p}$ for $\mathrm{TINO}_{3}$ according to two calorimetric investigations are shown in Fig. 2, where there is seen to be a small change in slope at $238 \pm 5 \mathrm{~K}$. Apparently undetected hitherto, this effect seems to exceed the experimental error; the two sets of data agreeing well in the region

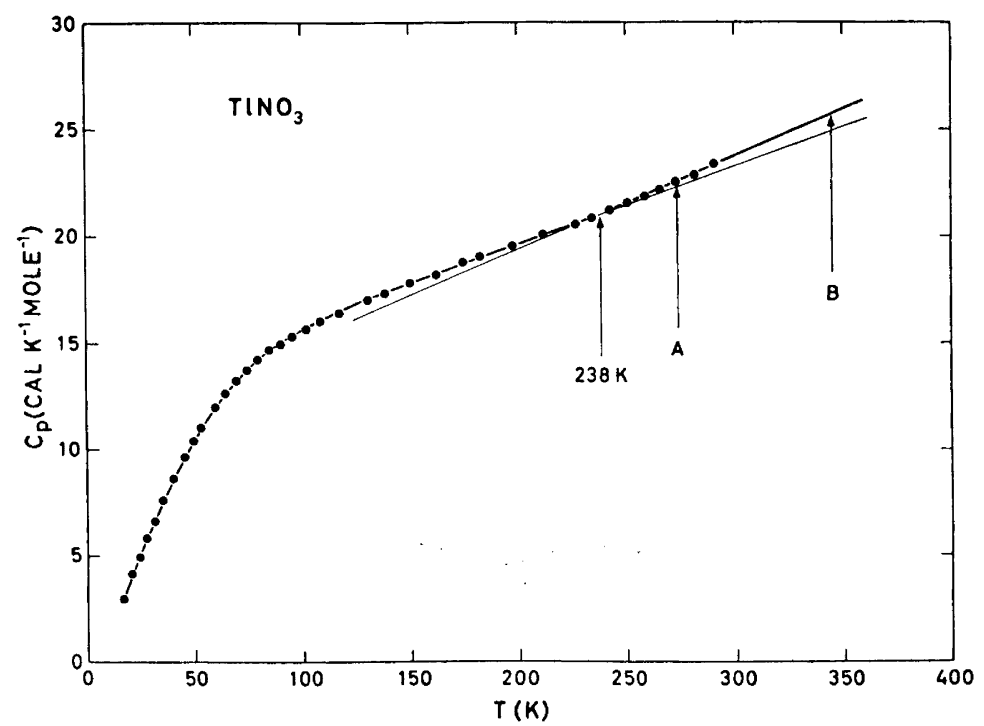

Fig. 2. The specific heat $c_{p}$ of $\mathrm{TINO}_{3}$ as a function of the absolute temperature $T$, showing a discontinuity of slope at $238 \pm 5 \mathrm{~K}$. The experimental points are from Latimer and Ahlberg, ${ }^{31}$ and the section $\mathrm{A}-\mathrm{B}$ of the curve is drawn according to the equation given by Satoh. ${ }^{32}$ 
of overlap. The anomaly may indicate a threshold in the bonding or disorder properties of the ions, and will be shown to coincide with a dielectric transition.

By means of optical spectroscopic and dilatometric observations, it was found that orthorhombic, room temperature phase IV crystals of $\mathrm{NH}_{4} \mathrm{NO}_{3}$ transform at $\sim 16^{\circ} \mathrm{C}$ into a tetragonal low temperature phase $\mathrm{V}$, of lesser birefringence. ${ }^{21}$ Samples were also found to be optically uniaxial at $-50^{\circ} \mathrm{C}$. By using a dilatometer, the same author found that on increasing the temperature, the expansion coefficient diminished at $-16^{\circ} \mathrm{C}$, and was followed by a region of contraction over the range -14 to $-8^{\circ} \mathrm{C}$, above which the crystals expanded normally. Later dilatometric experiments yielded the V $\rightarrow$ IV transition temperature of $-18^{\circ} \mathrm{C} .^{33}$ In common with several other univalent nitrate phases, the anions lie in parallel planes, in the present case parallel to $(010)$. $^{34-38}$

Although X-ray diffraction measurements indicated the symmetry of phase $\mathrm{V}$ to be hexagonal or pseudohexagonal, with only expansion differences between the unit cell dimensions at $-78,-33$, and $-18^{\circ} \mathrm{C},{ }^{36}$ the earlier suggestion of tetragonal symmetry, ${ }^{21}$ has been confirmed at $-50^{\circ} \mathrm{C} .^{37,38}$

Specific heat measurements showed a sharp peak in value at $-60.4^{\circ} \mathrm{C},{ }^{39}$ and this anomaly was later noted in addition to others at -160 and $-18^{\circ} \mathrm{C} .^{40}$ The transformations at -160 and $-60.4^{\circ} \mathrm{C}$ were absent from other calorimetric investigations, however, ${ }^{\mathbf{4 1}, \mathbf{4 2}}$ the temperatures reported for the $\mathrm{V} \rightarrow \mathrm{IV}$ and IV $\rightarrow$ III transitions being -16.9 and $32.2^{\circ} \mathrm{C}$.

Measurements of dielectric constant at $100 \mathrm{kHz}$ for a powdered sample showed an increase in value at $-33^{\circ} \mathrm{C}$ on cooling, and hysteresis to $-6^{\circ} \mathrm{C}$ on heating. ${ }^{43} \mathrm{~A}$ two-terminal conductivity measurement for $t>-25^{\circ} \mathrm{C}$, at a sample voltage of $200 \mathrm{~V}$, showed an anomaly at $\sim-6^{\circ} \mathrm{C}$ on heating. ${ }^{37}$

Observations of the electron paramagnetic resonance (EPR) of $\mathrm{VO}^{2+}$ included in the $\mathrm{NH}_{4} \mathrm{NO}_{3}$ lattice have shown that a rapid readjustment of the ion which is present at $25^{\circ} \mathrm{C}$ is totally absent at $-70^{\circ} \mathrm{C}$. The gradual onset of the motion appears to occur over the range -30 to $-20^{\circ} \mathrm{C} .^{44}$

An ideal study of the low frequency (or non-optical) properties of a compound would probably consist of measurements of the temperature dependence of the four-terminal conductivity and dielectric constant, virtually from d.c. to a practical upper limit in the radio frequency range. The investigation would also provide data on polarization barrier formation and the influence of substitutional impurities in single crystals; together with the detection of any non-linearity of displacement current. The effect of pressure upon the electrical parameters would also be determined. Actual investigations usually only fulfil part of these requirements, but nevertheless provide a useful addition to the information gained using other, and often more sophisticated techniques.

The present work was aimed primarily at discovering whether electrical anomalies of the type found in the alkali metal nitrates ${ }^{45-49}$ occur also in $\mathrm{AgNO}_{3}, \mathrm{TINO}_{3}$, and $\mathrm{NH}_{4} \mathrm{NO}_{3}$. Satisfactory techniques for the measurement of four-terminal resistivity and dielectric constant below room temperature in these compounds are still to be fully developed, and the series of measurements is therefore restricted to a.c. two-terminal parameters for polycrystalline samples. The measurements were extended above room temperature for $\mathrm{AgNO}_{3}$ and $\mathrm{TlNO}_{3}$.

Of the three compounds measured, $\mathrm{NH}_{4} \mathrm{NO}_{3}$ has been most thoroughly studied below room temperature, and it is the only univalent nitrate known

Acta Chem. Scand. 27 (1973) No. 10 
to have a structural phase transition in this region. It is not possible to reconcile all of the reported physical properties of the compound, however; and some extra complexity is to be expected when both ions are non-spherical.

\section{EXPERIMENTAL}

The p.a. grade compounds were finely divided by crushing, and dried under vacuum; $\mathrm{AgNO}_{3}$ (E. Merck A.G.) and $\mathrm{TINO}_{3}$ (Fluka A.G.) at $\sim 120^{\circ} \mathrm{C}$ for $24 \mathrm{~h}, \mathrm{NH}_{4} \mathrm{NO}_{3}$ (E. Merck A.G.) at $70^{\circ} \mathrm{C}$ for $1 \mathrm{~h}$. Laminar polycrystalline samples were then formed by cooling the melt between silver electrode plates of $\sim 10 \mathrm{~cm}^{2}$ area, spacers of quartz or Pyrex being used to obtain separations of $\sim 0.3 \mathrm{~mm}$.

The apparatus used to control the sample temperature and measure dielectric constant and dissipation at $1 \mathrm{kHz}$ were as described previously..$^{45,46}$

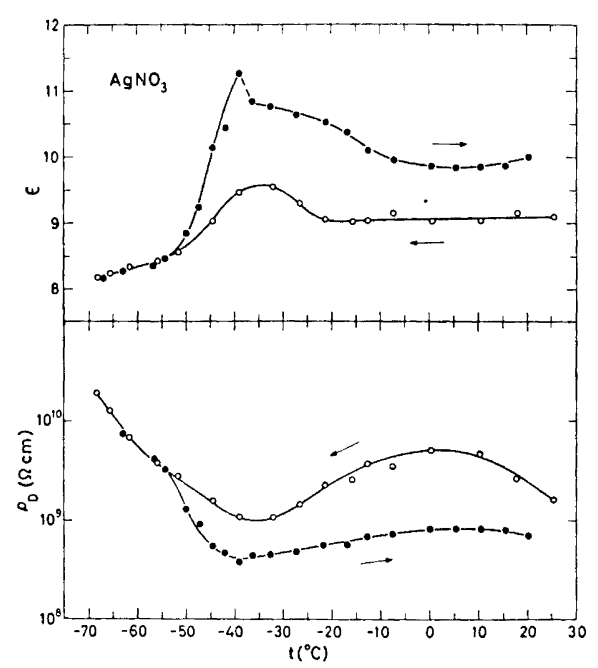

Fig. 3. Dielectric constant $\epsilon$ and resistivity $\varrho_{D}$ for $\mathrm{AgNO}_{3}$ as functions of temperature. In this and the following diagrams open circles denote values obtained with decreasing temperature; filled circles with increasing temperature.

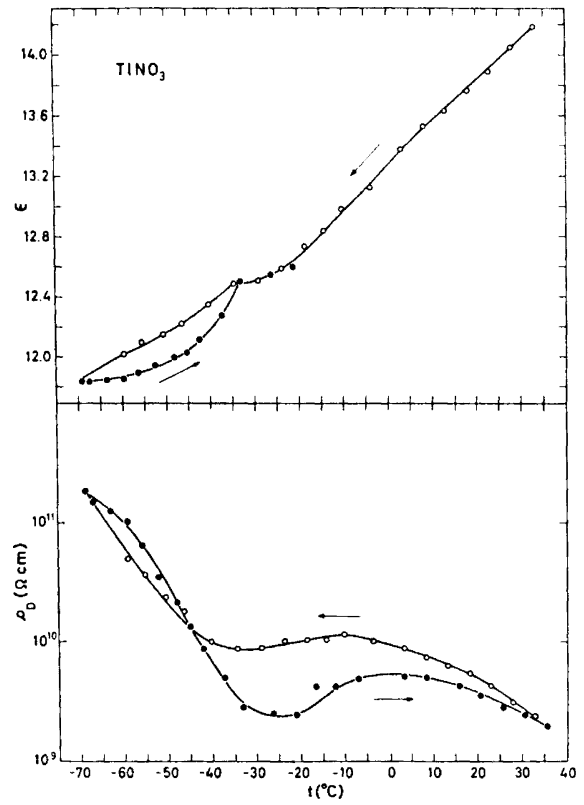

Fig. 4. Dielectric constant $\epsilon$ and resistivity $\varrho_{D}$ for $\mathrm{TlNO}_{3}$ versus temperature.

\section{RESULTS AND DISCUSSION}

Values of the dielectric constant $\epsilon$ and resistivity $\varrho_{D}$ at $1 \mathrm{kHz}$ for $\mathrm{AgNO}_{3}$, $\mathrm{TINO}_{3}$, and $\mathrm{NH}_{4} \mathrm{NO}_{3}$ below room temperature are shown in Figs. 3 to 5 , and results obtained above room temperature for $\mathrm{AgNO}_{3}$ and $\mathrm{TINO}_{3}$ in Figs. 6 and 7 . 


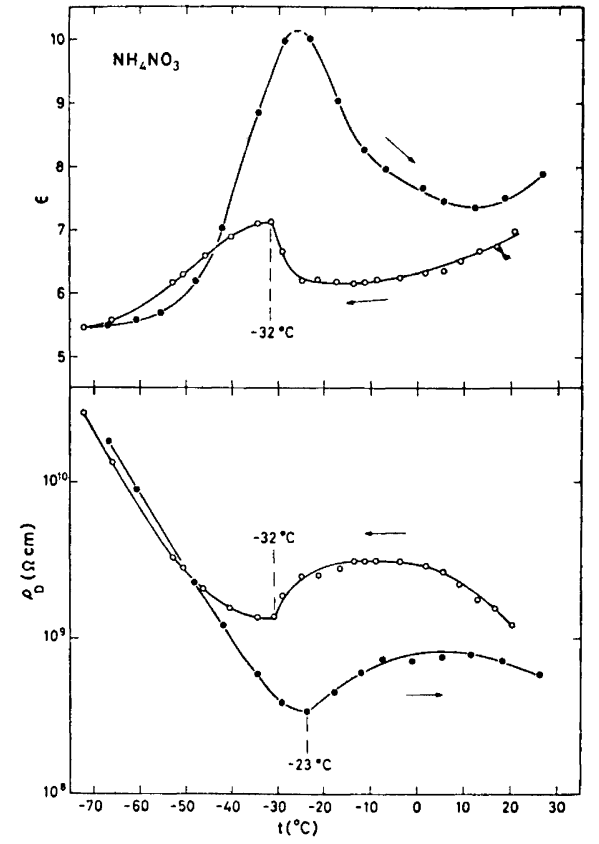

Fig. 5. Dielectric constant $\epsilon$ and resistivity $\varrho_{D}$ for $\mathrm{NH}_{4} \mathrm{NO}_{3}$ as functions of temperature.

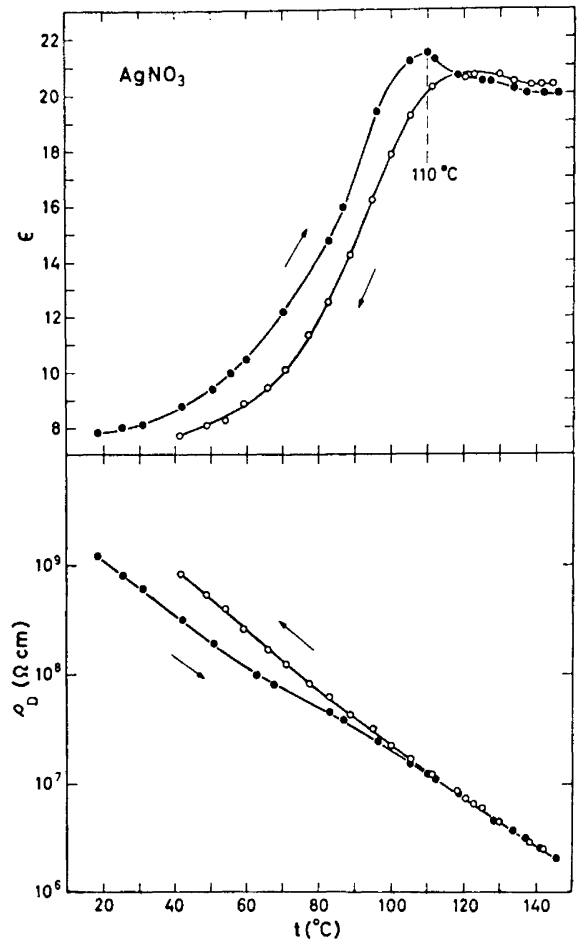

Fig. 6. Dielectric constant $\epsilon$ and resistivity $\varrho_{D}$ for $\mathrm{AgNO}_{3}$ versus temperature.

The form of the samples yielding these data is both convenient and suitable when the temperature variation of parameters rather than their absolute values are of primary interest. It is clear, however, that when a compound is allowed to freeze in contact with metal electrode plates, there is little control over the growth of the crystallites, which is governed by such factors as rate of cooling, degree of purity of the sample, condition of the electrode surface, etc. With anisotropic compounds the samples may include preferred directions of crystal growth, which are not easily ascertained. It may also be difficult to measure the sample geometry with high precision. Variations in absolute value from sample to sample have been found, and the results are therefore not necessarily those for a bulk sample of small, randomly oriented grains. The temperature dependent forms of the anomalies seen in the results are reproducible, however.

Below room temperature, the curves for $\mathrm{AgNO}_{3}, \mathrm{TlNO}_{3}$, and $\mathrm{NH}_{4} \mathrm{NO}_{3}$ show dielectric transitions which are similar in form to those found in the alkali metal nitrates. ${ }^{45-49}$ The temperatures marked on the curves are taken as being characteristic of the anomalies for the purpose of comparison. The forms of the anomalies suggest the presence of structural or order-disorder 


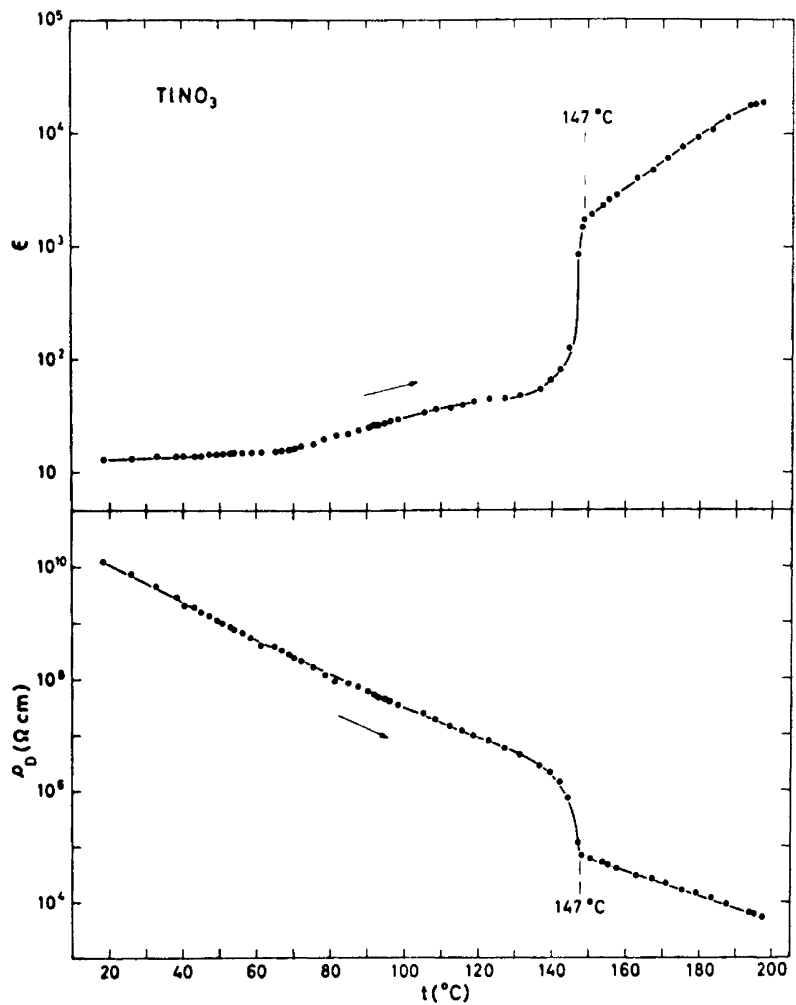

Fig. 7. Dielectric constant $\epsilon$ and resistivity $\varrho_{D}$ for $\mathrm{TlNO}_{3}$ as functions of temperature.

transformations in the compounds, and in the case of $\mathrm{TINO}_{3}$ the dielectric transition temperature of $-35^{\circ} \mathrm{C}$ (Fig. 4) agrees well with that of the discontinuity in slope of the specific heat curve of Fig. 2.

The maximum at $-32^{\circ} \mathrm{C}$ in the values of $\epsilon$ obtained on cooling for $\mathrm{NH}_{4} \mathrm{NO}_{3}$ (Fig. 5) is very similar to the effect found by Kamiyoshi and Yamakami ${ }^{43}$ at the same temperature. The latter authors employed a frequency of $100 \mathrm{kHz}$, and a powdered sample, and the differences between the two sets of data are no greater than may be expected from the techniques used. On heating, the present results show less hysteresis than those of Kamiyoshi and Yamakami.

The resistivity $\varrho_{D}$ of $\mathrm{NH}_{4} \mathrm{NO}_{3}$ (Fig. 4) reflects the course of $\epsilon$, showing that the increased polarizability is accompanied by relaxation. In addition, the $\varrho_{D}$ curves show slight, but important minima at $\sim-20^{\circ} \mathrm{C}$ on cooling and $\sim-3^{\circ} \mathrm{C}$ on heating. The latter effect corresponds to the d.c. conductance anomaly found by Brown and McLaren at $\sim-6^{\circ} \mathrm{C}$ on heating, and identified as being due to the $V \rightarrow I V$ transformation. ${ }^{37}$ From a comparison of these results, it appears that the dielectric transitions do not coincide with the $I V \rightleftharpoons V$ transformations, and that negligible changes in $\epsilon$ are associated with the structural 
transitions, although variations in a.c. and d.c. resistivity do occur. This interpretation is supported by the large discrepancy between the dielectric transition temperature $\left(-32^{\circ} \mathrm{C}\right)$ and that detected by other means $\left(\sim-18^{\circ} \mathrm{C}\right)^{*}$ on cooling.

On the other hand, the anomalous variations of $\epsilon$ and $\varrho_{D}$ for $\mathrm{NH}_{4} \mathrm{NO}_{3}$ below room temperature are clearly of the same nature as those found in the other univalent nitrates, implying that the effect is not a disorder property of the $\mathrm{NH}_{4}{ }^{+}$ion, although the latter could be involved in the $\mathrm{V} \rightarrow \mathrm{IV}$ transformation. It may be significant that the EPR measurements ${ }^{44}$ on $\mathrm{NH}_{4} \mathrm{NO}_{3}$ containing $\mathrm{VO}^{2+}$ showed the onset of rapid reorientation of the ion to occur over the hysteresis interval of the dielectric transition. This is not the case for $\mathrm{NaNO}_{3}, \mathrm{KNO}_{3}$, and $\mathrm{CsNO}_{3}$, however. ${ }^{44}$

The results for $\mathrm{AgNO}_{3}$ above room temperature (Fig. 6) show a maximum in $\epsilon$ at $110^{\circ} \mathrm{C}$, succeeded by a plateau region at higher temperatures. The increase in $\epsilon$ of $\sim 2.5$ times the room temperature value is not associated with an increase in dissipation, the values of $\varrho_{D}$ being substantially linear, especially on cooling. Thus the increased polarizibility involves purely elastic displacements or rotations. It is not known whether the anomaly is reflected in the d.c. resistivity, the measurements of Davis et al..$^{18}$ commencing above $110^{\circ} \mathrm{C}$. The dielectric anomaly does not appear to be directly connected with the $\mathrm{II} \rightarrow \mathrm{I}$ transformation at $\sim 160^{\circ} \mathrm{C}$.

The data obtained for $\mathrm{TINO}_{3}$ above room temperature (Fig. 7) show a gradual increase in $\epsilon$ above $\sim 70^{\circ} \mathrm{C}$, i.e. in the phase II region. The onset of the II $\rightarrow I$ transition is gradual, and the change completed at $147^{\circ} \mathrm{C}$. The rather steeply increasing value of $\epsilon$ in phase I resembles those of the isostructural phase III of $\mathrm{RbNO}_{3} \cdot{ }^{49}$ No appreciable change in $\varrho_{D}$ occurs at III $\rightarrow$ II, in accordance with the use of a dry sample ( $c f$. Ref. 22). Apart from the effects of the II $\rightarrow$ I transition, which has a gradual onset, the variation in resistivity is substantially linear. Of all of the known structural transformations in univalent nitrates, the III $\rightarrow$ II transition in $\mathrm{TINO}_{3}$ has the least effect upon the electrical parameters.

Acknowledgement. This work was made possible by the financial support of Norges almenvitenskapelige forskningsråd.

\section{REFERENCES}

1. Arell, A. Ann. Acad. Sci. Fennicce Ser. A VI 1962 No. 100.

2. Bridgman, P. W. Proc. Am. Acad. Arts Sci. 51( 1916) 579.

3. Bridgman, P. W. Proc. Am. Acad. Arts Sci. 72 (1937) 44.

4. Smith, W. V., Brown, O. L. I. and Pitzer, K. S. J. Am. Chem. Soc. 59 (1937) 1213.

5. Janz, G. J., James, D. W. and Goodrin, J. J. Phys. Chem. 64 (1960) 937.

6. Gordon, S. and Campbell, C. Anal. Chem. 27 (1955) 1102.

7. Patil, K. C., Gosavi, R. K. and Rao, C. N. R. Inorg. Chim. Acta 1 (1967) 155.

8. Murphy, J. W. and Wetmore, F. E. W. Can. J. Chem. 37 (1959) 1397.

9. Fischmeister, H. F. J. Inorg. Nucl. Chem. 3 (1956) 182.

10. Levin, E. M. J. Am. Ceram. Soc. 52 (1969) 53.

11. Zachariasen, W. H. Skrifter Norske Videnskaps-Akad. Oslo I. Mat. Naturv. Kl. 1928 No. 4.

* See introductory section.

Acta Chem. Scand. 27 (1973) No. 10 
12. Swanson, H. E., Gilfrich, N. T. and Ugrinic, G. M. Natl. Bur. Std. (U.S.) Circ. No. 539, V (1955) p. 59.

13. Washbuen, E. W. (Ed.) International Critical Tables Vol. VII, McGraw, New York 1930.

14. Tessman, J. R. and Kahn, A. H. Phys. Rev. 92 (1953) 890.

15. Landolt-Börnstein 6th Ed., Vol. I, Part 4, Springer, Berlin-Göttingen-Heidelberg 1955.

16. Newman, R. and Halford, R. S. J. Chem. Phys. 18 (1950) 1276.

17. Ferraro, J. R. and Walker, A. J. Chem. Phys. 42 (1965) 1273.

18. Davis, W. J., Rogers, S. E. and Ubbelohde, A. R. Proc. Roy. Soc. (London) Ser. A 220 (1953) 14.

19. Cerisier, P. and Bizouard, M. Compt. Rend. 261 (1965) 5100.

20. Eucken, A. and Büchner, A. Z. physik. Chem. B 27 (1934) 321.

21. Wallerant, F. Bull. Soc. Franc. Mineral. 28 (1905) 311.

22. Brown, R. N. and McLaren, A. C. Acta Cryst. 15 (1962) 977.

23. Rolla, M., Franzosini, P. and Riccardi, R. Discussions Faraday Soc. 32 (1961) 84.

24. Finbak, C. and Hassel, O. Z. physik. Chem. B 35 (1937) 25.

25. Rivoir, L. and Abbad, M. Anales Fis. Quim. (Madrid) 39 (1943) 306.

26. Ferrari, A. and Cavalca, L. Gazz. Chim. Ital. 80 (1950) 199.

27. Hinde, R. M. and Kellett, E. A. Acta Cryst. 10 (1957) 383.

28. Roberts, S. Phys. Rev. 76 (1949) 1215.

29. Miller, W. H. Proc. Roy. Soc. (London) 14 (1865) 555.

30. Komatsu, H. Rept. Inst. Sci. Technol. Univ. Tokyo 5 (1951) 15.

31. Latimer, W. M. and Ahlberg, J. E. J. Am. Chem. Soc. 54 (1932) 1900.

32. Satoh, S. Bull. Inst. Phys. Chem. Res. (Tokyo) 21 (1942) 127.

33. Behn, U. Proc. Roy. Soc. (London) Ser. A 80 (1908) 444.

34. Bragg, W. H. Trans. Faraday Soc. 20 (1924) 59.

35. West, C. D. J. Am. Chem. Soc. 54 (1932) 2256.

36. Hendricks, S. B., Posnjak, E. and Kracek, F. C. J. Am. Chem. Soc. 54 (1932) 2766.

37. Brown, R. N. and McLaren, A. C. Proc. Roy. Soc. (London) Ser. A 266 (1962) 329.

38. Hendricks, S. B., Deming, W. E. and Jefferson, M. E. Z. Krist. 85 (1933) 143.

39. Crenshaw, J. L. and Ritter, I. Z. physik. Chem. B 16 (1932) 143.

40. Jaffray, J. Compt. Rend. 224 (1947) 1346.

41. Stephenson, C. C., Bentz, D. R. and Stevenson, D. A. J. Am. Chem. Soc. 77 (1955) 2161.

42. Nagatani, M., Seiyama, T., Sabiyama, M., Suga, H. and Syuzo, S. Bull. Chem. Soc. Japan 40 (1967) 1833.

43. Kamiyoshi, K. and Yamakami, T. Sci. Rep. Tohoku Univ. A 11 (1959) 418.

44. Rao, K. V. S., Sastry, M. D. and Venkateswarlu, P. J. Chem. Phys. 52 (1970) 4035.

45. Fermor, J. H. and Kjekshus, A. Acta Chem. Scand. 22 (1968) 836.

46. Fermor, J. H. and Kjekshus, A. Acta Chem. Scand. 22 (1968) 1628.

47. Fermor, J. H. and Kjekshus, A. Acta Chem. Scand. 22 (1968) 2054.

48. Fermor, J. H. and Kjekshus, A. Acta Chem. Scand. 23 (1969) 1581.

49. Fermor, J. H. and Kjekshus, A. Acta Chem. Scand. 26 (1972) 2645.

Received June 28, 1973. 